\title{
ENTREVISTA FRANÇOIS DUBET
}

Professor emérito da Universidade de Bordeaux e diretor de estudos na Escola de Altos Estudos em Ciências Sociais de Paris, François Dubet realizou, ao longo de sua longeva e prolífica trajetória acadêmica, pesquisas em campos tão diversos quanto movimentos sociais, marginalidade juvenil, delinquência, trabalho e educação.

Para além de sua profundidade analítica, toda essa produção tem em comum o emprego de uma original abordagem teórico-metodológica que o sociólogo denomina "sociologia da experiência" (DUBET, 1994). Dubet define o conceito de "experiência social" como "a cristalização, mais ou menos estável, em indivíduos e grupos, de diferentes lógicas de ação, por vezes opostas, que os atores são obrigados a combinar e hierarquizar para se constituírem como sujeitos" (DUBET, 20I7, p. IOO-IOI, tradução nossa).

Com base nessa definição, o autor propõe um instrumental analítico capaz de lançar luz sobre a experiência dos atores, sem colocá-los numa posição de marionete que apenas reproduz a lógica sistêmica, nem ignorar condicionamentos a que estão sujeitos. É sobre esse pano de fundo que Dubet publicou a trilogia fundamental de sua teoria sociológica Sociologia da experiência (1994), Le déclin de l'institution (2002) e Le travail des sociétés (2009) bem como as obras destinadas a análises de conjuntura de caráter mais ensaístico.

$\mathrm{Na}$ última delas, O tempo das paixões tristes (2020), Dubet analisa as consequências da excessiva individualização das experiências de desigualdades, apontadas por ele como a origem de "paixões tristes", como cóleras, ressentimentos e indignações que têm estado presente nas ruas de diversos países nos últimos anos. Esse é o tema que permeia esta entrevista, em que o autor analisa questões como o populismo, o enfraquecimento das identidades de classe, a multiplicidade de movimentos sociais na contemporaneidade, a crise que atinge tanto as democracias jovens quanto as historicamente mais consolidadas e o papel da sociologia nesse cenário.

As perspicazes reflexões do autor são um convite a uma sociologia crítica, capaz de contribuir para a compreensão e a superação dos desafios contemporâneos. "Deixar-se afundar no pessimismo", conclui, "é uma falha moral". 
François Dubet foi entrevistado por Taísa Sanches, pesquisadora de pós-doutorado do Programa de Pós-graduação em Ciências Sociais da Pontifícia Universidade Católica do Rio de Janeiro (PUC-Rio) e doutora em Ciências Sociais pela mesma instituição; e Daniel Fassa Evangelista, doutor em Ciências Sociais pela PUC-Rio e professor da Faculdade Católica Salesiana (FSMA-RJ). Tradução de Sylvia Alencar.

Desigualdade \& Diversidade: Seu último livro, O tempo das paixões tristes, dialoga muito com o tema do dossiê proposto para este número da revista (n- 2I). Neste livro, você aponta a desconfiança em relação à democracia representativa e à transformação do sistema de desigualdade como responsáveis pela individualização das experiências de desigualdade. Você poderia explicar um pouco mais essa individualização? Você considera que as pessoas não se sentem mais dentro de uma estrutura de desigualdades de classes?

François Dubet: Gostaria de esclarecer que esse meu raciocínio diz respeito às antigas sociedades industriais nacionais europeias e norte-americanas. Quero dizer com isso que não creio que seja aplicável ao Brasil, à Argentina, à Venezuela ou ao Chile. O modelo que os sociólogos inventaram e teorizaram foi uma representação das sociedades industriais e nacionais. O que significa isso? Significa que, pouco a pouco, foi se criando um sistema de desigualdades estruturado em torno das classes sociais. O indivíduo era um trabalhador, um camponês, um pequeno burguês ou um patrão, mas essa pessoa pertencia a uma classe social que tinha uma identidade de classe, uma cultura de classe, uma consciência de classe - digamos, para simplificar -, e essa visão de sociedade era comum a todos os sociólogos. Você a encontra na obra de Durkheim, de Parsons, de Marx e de Weber. É desse modo que pensamos a sociedade.

A segunda coisa é que aquelas eram sociedades que percebiam a si próprias como sociedades nacionais e soberanas. Havia a ideia de uma base cultural nacional comum. Estaria até disposto a dizer que são cantilenas, são historinhas, que isso não é verdade, mas é assim, porém, que vemos as coisas em que, progressivamente, os imigrantes vão se integrar, e os espanhóis vão se tornar franceses, os alemães vão se tornar americanos... Bem, pode ser que não funcione assim para todos, mas é dessa maneira que nós representamos as coisas. A democracia é, ao mesmo tempo, a representação dessas classes no espaço político - a esquerda representa os trabalhadores, os pequenos funcionários públicos etc.; a direita representa os camponeses, os patrões, os católicos -, temos aqui a ideia de que a vida política representa a sociedade; e, ao mesmo tempo, a vida política representa a unidade da própria sociedade, as instituições, a escola. O Estado representa a unidade da sociedade. 
Creio que essa representação da vida nas sociedades mencionadas está se desfazendo. Não porque as desigualdades estejam desaparecendo, longe disso, mas porque as desigualdades estão sendo transformadas. Elas estão mudando na medida em que estão cada vez menos estruturadas por desigualdades de classe. Hoje em dia, um indivíduo não diz mais "eu sou um operário", e tudo o mais é decorrência disso: sua representação da cultura, seu modo de vida, suas escolhas políticas, tudo decorre dessa identidade de classe trabalhadora. Agora, todos os indivíduos dizem: "eu sou desigual como...". Portanto, o que há, basicamente, é uma explosão de desigualdades, pois os indivíduos dizem: "Eu sou desigual enquanto trabalhador, enquanto graduado, enquanto uma pessoa branca, enquanto uma pessoa não branca, enquanto mulher, enquanto homem, enquanto uma pessoa que vive em Paris ou que vive nas províncias, enquanto uma pessoa jovem, enquanto uma pessoa de idade...". De alguma maneira, os indivíduos que antes tinham a sensação de estar presos a uma estrutura de desigualdade, hoje têm a experiência inversa, de que as desigualdades explodem e se individualizam. É muito impressionante ver como tudo mudou. Por exemplo, 30 anos atrás, podíamos dizer: "diga-me a posição profissional de um indivíduo, eu lhe direi como ele se comporta". Hoje isso não é mais possível, porque... ele é jovem, ele é velho, ele vive em São Paulo, ele vive no Norte, ele é homossexual, ele é homem, ele é mulher, ele seguiu os estudos, ele não seguiu os estudos... E, assim, todo o mundo explode! O que não significa que não haja desigualdades, evidentemente, mas essas desigualdades são vivenciadas no plano individual. Isso teve um impacto enorme na representação política, como por exemplo, na França ou nos Estados Unidos, onde, anteriormente, o que havia era um voto de classe, mas hoje as classes populares não votam mais majoritariamente na esquerda. Ou eles não votam mais, ou então eles votam... (sei que é preciso ter muito cuidado com o vocabulário ao falarmos com latinos) no candidato populista, ou na extrema direita, ou na extrema esquerda, mas já não votam mais nos sindicatos, nos partidos tradicionais. Aliás, na maioria das vezes, nem votam mais, porque não se sentem mais representados. Percebe-se, então, uma desigualdade que, antes, era uma experiência coletiva que protegia os indivíduos - minha dignidade era protegida pela minha classe social - e que, hoje, é uma experiência individual. Isso faz com que o sentimento dominante - dominante! - hoje, na Europa Ocidental e na América do Norte, seja o sentimento de ser desprezado. Antes, as pessoas diziam: "Eu sou explorado"; agora as pessoas dizem: "Eu sou desprezado". Então, "sou desprezado porque sou homem, porque sou mulher, porque sou homossexual, porque sou heterossexual, porque tenho diplomas que não são reconhecidos, porque não tenho diploma, porque sou mal pago, porque meu trabalho é difícil e não é reconhecido" etc. Há, portanto, toda uma retórica que diz, basicamente, "as desigualdades são uma experiência subjetiva de desprezo, de indignidade"; e a crise da democracia consiste, obviamente, em que se tornou muito difícil representar politicamente esse sentimento de desprezo. E é aqui que temos o que, na 
Europa, se chama (embora isso não corresponda exatamente ao vocabulário argentino, em particular) populismo. Há líderes que dizem - e Bolsonaro é desse tipo: "Eu sou o povo, eu entendo vocês, eu sou como vocês, eu também estou sendo desprezado", "sou desprezado pelos intelectuais, sou desprezado pela esquerda, sou desprezado pela mídia, ninguém me entende". Por consequência, hoje temos uma crise da democracia.

Existe hoje um perigo real para a democracia, em diversos países, inclusive em países democráticos, como Hungria e Polônia, que estão se tornando cada vez menos democráticos e onde vemos isso acontecer. Pois essa é a primeira mudança importante: "Não estou mais sendo representado, sou desprezado, eu sou o povo". É claro que dizer "eu sou o povo" não significa nada, porque o próprio povo está dividido. Então, a primeira mudança significativa é que nós saímos das sociedades industriais nacionais. A globalização faz com que não haja mais sociedades industriais nacionais com economia e cultura próprias. E o que todos os populistas querem, evidentemente, é retornar a uma cultura nacional, a uma economia nacional.

A segunda mudança, ainda no contexto das sociedades que mencionei - Europa Ocidental, Canadá, Estados Unidos - é que a concepção dominante de justiça social nas sociedades de classe era a redução das desigualdades entre as classes. Não era dizer: "os trabalhadores devem se tornar patrões", mas sim, afirmar: "os trabalhadores devem ser mais bem pagos, mais dignos, mais bem protegidos, mais educados, estar com saúde melhor etc.". Então, o modelo de justiça era dizer: "É preciso reduzir as desigualdades entre os mais ricos e os mais pobres", e foi isso que foi feito, a grosso modo, entre I900 e 1980, na Alemanha, na Inglaterra, na França, nos Estados Unidos e no Canadá, onde as desigualdades foram reduzidas. Esse conceito de justiça fundamentava-se nas classes sociais e no trabalho. Eram o trabalho e as classes sociais que proporcionavam consistência a esse conceito de justiça. Hoje mudamos completamente para outro conceito de justiça, que é o da igualdade de oportunidades de acesso a todas as posições sociais. A justiça já não consiste mais em reduzir as desigualdades entre os indivíduos, ela agora consiste em garantir, a todos os indivíduos, as mesmas oportunidades de acesso a todas as posições sociais. Assim, o vocabulário da justiça deixa de ser o vocabulário da redução das desigualdades entre as posições sociais, e passa a ser o vocabulário da luta contra a discriminação.

Existe hoje até uma luta entre os discriminados. Os "brancos pobres", os "poor whites" que votam no Trump, aqueles que, na França, votam na extrema direita, dizem: "nós somos discriminados porque somente os outros discriminados estão sendo cuidados, as minorias negras, muçulmanas, as mulheres etc.". Percebe-se, aqui, uma mudança no conceito de justiça, à qual a maioria dos intelectuais e dos sociólogos adere atualmente. Quando denunciam desigualdades, são as discriminações que estão denunciando, quase sem perceber que, na verdade, isso significa o triunfo do modelo liberal, no qual uma 
sociedade justa é uma sociedade que se assemelharia a uma competição esportiva equânime, na qual todos teriam chances iguais de vencer. O que, obviamente, é absurdo por dois motivos: em primeiro lugar, porque todo mundo não têm as mesmas chances; e, em segundo lugar, porque, de qualquer maneira, sempre haverá vencidos, e a prioridade, ainda assim, são os vencidos. Então, o que temos, essencialmente, é uma sociedade em que as desigualdades se individualizaram - é esta a minha tese - e são vivenciadas com discriminação, mágoa, sofrimento, desprezo. Isso não é nem bom, nem ruim, apenas é assim, mas traz um problema realmente importante, que é o de como dar uma expressão política a isso, pois já podemos perceber que se tornou extremamente difícil pelo fato de existirem milhares de discriminações.

Outra coisa que mudou e que, apesar de este não ser meu campo de expertise, me parece muito importante, algo que os brasileiros conhecem melhor do que ninguém, são as redes sociais. Os partidos políticos e os sindicatos eram máquinas que abrandavam a ira, que organizavam as pessoas, que elaboravam programas. As pessoas ficavam com raiva, e o sindicato ou o partido dava uma forma política a essa raiva, abrandava essa ira. Hoje, vemos que qualquer pessoa tem a impressão de poder ser, ela própria, um movimento social, de poder dizer diretamente o que ela pensa e, por isso, tem a impressão de que já não precisa mais das instituições democráticas. Vemos isso de maneira quase patológica na França hoje, mas também no Brasil, nos debates sobre as vacinas, sobre a vacinação e a Covid-I9. Todo mundo se tornou especialista em vacinas. Todo mundo! Isso é ridículo, certamente, mas ainda assim é muito perigoso. Essa evolução é superdemocrática, por um lado, trata-se de uma boa evolução, porque não precisamos mais dos intelectuais, dos jornalistas, dos clérigos ou dos cientistas que mantinham certo domínio sobre as expressões sociais; mas o desaparecimento desses mediadores, no entanto, faz com que se crie a impressão de que as instituições políticas já não são mais necessárias. Na França, houve um movimento grande que se chamou Coletes Amarelos. Eram pessoas que estavam revoltadas e que, durante um ano, fizeram manifestações, mas não chegaram a formular nenhuma exigência política porque o que tinham era uma soma de exigências individuais. Os governos se reuniam com pessoas com as quais não se podia discutir. É possível discutir com os sindicatos ou com os partidos políticos, mas não se pode discutir com um milhão de indivíduos que têm um milhão de opiniões diferentes. Essas questões são realmente muito importantes. Observamos claramente, hoje em dia, que os políticos não são mais produzidos pelos partidos, eles são produzidos pelas redes. São as redes sociais que os fabricam. Trump conta mais com as redes do que com o Partido Republicano. Na França, os candidatos populistas contam mais com as redes do que com os partidos. Portanto, penso que vivemos um momento, pelo menos nesta parte do mundo, em que os mecanismos democráticos e institucionais, as classes sociais, as nações em que vivemos, as quais integramos, tudo isso está em vias de desaparecer e, por conseguinte, a meu ver, estamos vivendo um momento 
que podemos considerar como muito preocupante. Embora períodos como este já tenham ocorrido na história, tornou-se evidente que teremos de encontrar outras formas de expressão democrática, caso contrário, iremos viver em uma espécie de face a face com opiniões públicas possivelmente incoerentes e com Estados cada vez mais autoritários. Existe, portanto, uma verdadeira questão em jogo, e penso que, de certa maneira, todos os países estão passando por isso. Vou dar alguns exemplos. Existem países muito "igualitários", como os países escandinavos, a Dinamarca, a Suécia, com baixo desemprego, baixa desigualdade, mas onde os partidos populistas são extremamente poderosos. Eles eram muito poderosos na Itália. Na França, eles ainda são muito poderosos. Na Inglaterra, isso se chamou Brexit. Vivemos, portanto, um momento em que o paradoxo é que as desigualdades estão aumentando, como dizem muitos economistas e sociólogos; mas, para mim, o fenômeno maior não é que elas estejam aumentando, mas sim que elas estejam se transformando, que sejam de outra natureza, que as pessoas tenham uma experiência diferente das desigualdades.

D\&D: Você afirma, também, que a estrutura das desigualdades de classe está difratada em experiências individuais de sofrimento que levam ao populismo. De fato, a estrutura social das classes está se transformando. Houve uma retração do Estado e uma perda de direitos que contribuiriam para que as pessoas não acreditassem mais nas instituições formais de representação social. Você acha que os movimentos sociais podem ser incluídos nessa categoria de instituição formal? Existem iniciativas que podem ser consideradas representativas das pessoas que individualizam o sofrimento?

FD: Creio que temos, hoje, uma multidão de movimentos sociais. O que não temos, o que já não temos mais, é aquilo que se costumava chamar "o movimento social", o imaginário político - o imaginário francês, inglês, alemão -, o imaginário político no qual o movimento operário ia agregando os sentimentos de injustiça. Hoje, pelo contrário, temos a impressão de que há um monte de movimentos sociais, isto é, que existem movimentos de minorias culturais que são, eles próprios - e insisto nisso -, ambivalentes: alguns pedem para ser menos visíveis, ao passo que outros pedem para ser mais visíveis. "Quero ser reconhecido como muçulmano", ou, pelo contrário, "não quero ser visto como muçulmano, quero ser um cidadão como qualquer outro". Quanto às mulheres, há aquelas que são a favor da igualdade e outras, pelo contrário, que são a favor da acentuação das diferenças de gênero. Você mesmo descreveu assim. Todos os movimentos estão se despedaçando de algum modo, é evidente, mas isso pode ser uma boa notícia; as sociedades não são nada apáticas, elas mudam enormemente. O problema hoje é que o sofrimento social precisa de respostas políticas. E quando ele não obtém respostas políticas, pode apelar à violência, ao ódio. $\mathrm{O}$ que aconteceu nos Estados Unidos, com a derrota de Trump, foi realmente extraordinário, analisando bem. Havia gente dizendo "o jogo político não faz sentido para mim. É o meu próprio sofrimento, de homem branco, que conta"; e, de certa maneira, "já não confio nas instituições". Portanto, hoje, acredito que o que está em jogo é uma questão política e, claro, uma questão intelectual. 
Se as ciências sociais podem servir a algum propósito, é ao de nos ajudar a compreender as situações em que estamos. Houve até algumas boas notícias, e eu queria insistir particularmente em uma delas, à qual não se deu muita atenção: o Chile teve um movimento social muito forte, no estilo dos Coletes Amarelos, com pessoas revoltadas lutando contra a polícia, mas que encontraram uma saída política, elegendo uma constituinte. Não se sabe muito bem em que isso vai dar, mas essas pessoas conseguiram encontrar uma resposta política, e não ficaram apelando, ao mesmo tempo, para a violência e por um Estado autoritário, como poderia ter acontecido, pois elas poderiam ter regressado a algo análogo a Pinochet. Mas houve uma resposta política, por isso creio que as sociedades podem encontrar respostas políticas.

D\&D: Nesses últimos anos, temos visto tanto no Brasil quanto na França - com ressalva das particularidades locais - o surgimento de locais de protestos marcados por uma grande diversidade interna, como as manifestações de junho de 2013, no Brasil; e os Coletes Amarelos, na França. Nessas ocasiões, surgiram tensões frequentes entre os próprios manifestantes, relacionadas justamente com as diferenças ideológicas decorrentes de experiências sociais diversas. Como podemos interpretar esse fenômeno?

FD: Creio que a interpretação seja simples. Observei as demonstrações dos Coletes Amarelos e fui ver também as manifestações contra as vacinas da Covid-I9. O que mais chama nossa atenção é ver que temos comunidades emocionais, pessoas que estão felizes por estarem juntas, mas que nada têm em comum. Com isso, quero dizer que cada Colete Amarelo tem a própria reivindicação, a própria luta, e que não existe uma luta em comum, exceto por "Abaixo o governo", "Fora os estrangeiros", enfim, coisas totalmente irreais. Dessa maneira, eles não conseguem construir uma reivindicação comum. E, pior ainda, eles tentam com afinco destruir qualquer possibilidade de reivindicação comum, ao afirmar: "não reconheço os porta-vozes".

Quando olhamos para uma manifestação contra as vacinas, na França, vemos a ultraesquerda e a extrema-direita manifestando juntas, sem que isso lhes cause qualquer problema, já que estão fora do âmbito das reivindicações. O grande perigo, naturalmente, é que surja uma oferta política, que chamamos de populista ou autoritária, a qual cria uma forma de unidade de estilo autoritário do tipo "nós somos a nação contra os estrangeiros", "somos o povo contra os judeus" - é isso que temos ouvido hoje em dia -, "somos os brancos contra os negros" etc. Esse é o grande risco porque, a meu ver, não existe uma verdadeira unidade de reivindicação. Agora, quando olhamos para os movimentos minimamente organizados, lá também não há uma verdadeira unidade. Não há uma unidade tão forte como pensávamos. Portanto, do meu ponto de vista, o desafio ainda é o de reconstruir objetivos coletivos que superem essa fragmentação. A vantagem da velha luta de classes, que desapareceu, era ter um propósito comum. Era dizer às mulheres, por exemplo, "o socialismo resolverá a questão das mulheres", o que é falso; ou então era dizer: "a questão das mulheres será tratada pelo movimento dos trabalhadores", "a questão da discriminação será tratada pelo movimento dos trabalhadores". Hoje, como ninguém mais pensa assim, não há mais uma convergência das lutas. A única convergência é a ira. Essas pessoas estão com raiva, é isso. Ou então, têm medo. Ontem eu estava vendo nos jornais 
vários artigos sobre as manifestações em apoio ao presidente Bolsonaro. A única coisa que une essas pessoas é que elas estão com medo, elas têm medo dos outros. O que temos aqui são os germes do "fascismo", ou qual seja o nome que se queira dar a isso.

D\&D: Ainda a esse respeito, no Brasil, essas tensões aumentaram consideravelmente, desde 2013, o que gerou uma grande polarização política e ideológica na sociedade, e culminou com a eleição de um presidente que tentou continuamente destruir as instituições republicanas e democráticas do país. Como explicar a propagação, dentro da sociedade, de ideologias em que o adversário é visto como um inimigo a ser eliminado e a política é vista como um jogo de soma zero? Você acha que a ascensão de governos autoritários está ligada a esse fenômeno?

FD: Incontestavelmente, essas escaladas autoritárias estão ligadas a esses fenômenos porque, quando estávamos em uma sociedade de classes, os patrões e os trabalhadores se opunham ou se confrontavam, até de maneira bastante violenta, mas eles tinham em comum um laço que era o trabalho e a fábrica. Eles pertenciam ao mesmo mundo, então, havia muita violência, mas estavam no mesmo mundo: faziam-se carros, fazia-se carvão, faziam-se aviões, e assim por diante. As pessoas viviam em sociedades que tinham a percepção de serem sociedades nacionais, nas quais, qualquer que fosse sua posição social, você pertencia ao imaginário nacional. Você era francês, você era inglês, você era alemão, você era norte-americano. Creio que, hoje, o mundo econômico explodiu de tal modo que as pessoas não têm mais a sensação de pertencer à mesma unidade econômica. Afinal de contas, eu compro uma camisa que é feita na China, meu computador é feito no Japão, meu carro é feito na Alemanha, os filmes que vejo são feitos nos Estados Unidos, enfim, não existe mais essa unidade. A ideia de que as sociedades são culturalmente homogêneas é uma ideia que, hoje em dia, não resiste mais à diversidade cultural, à imigração. Existem certas forças autoritárias que dizem: "vamos voltar à economia nacional de antes, vamos voltar à unidade nacional, vamos expulsar os estrangeiros, os muçulmanos, as mulheres, enfim, vamos expulsar todos aqueles que não fazem parte da nação e retornar a uma economia nacional", o que é absurdo, evidentemente, mas que, de fato, constitui a demanda autoritária. Creio que as mutações do mundo estão a tal ponto violentas que estão provocando um estado de pânico. Hoje as pessoas dizem: "não reconheço mais a minha sociedade", "sou estrangeiro na minha própria sociedade". Claro, isso depende de cada país, mas o perigo autoritário está presente, de fato, e é muito, muito poderoso. $\mathrm{O}$ Brasil sabe disso muito bem.

D\&D: Você afirma que as manifestações de raiva que até recentemente ficavam limitadas à esfera privada agora estão sendo expostas na esfera pública sem que seja possível, para os indivíduos, refletir sobre quais são as causas disso. Você acredita que a dificuldade em racionalizar as reivindicações venha apenas daqueles que se sentem discriminados? Qual é o papel do Estado nesse diagnóstico? Como poderia um governo não populista se reposicionar na sociedade para lidar com as múltiplas desigualdades?

FD: A resposta não é simples porque o Estado não tem tanto poder assim atualmente. Eu persisto em pensar que as redes sociais são uma revolução absoluta. No passado, o Estado podia dizer: "eu lhe dou o direito", "eu não lhe dou o direito", "eu lhe dou o direito de se reunir", "eu não lhe dou o direito de se reunir", "estas são as ideias que podem ser 
ditas", "estas são as ideias que não podem ser ditas". Nenhum Estado, hoje, em lugar nenhum, pode dizer isso. Veja o Estado chinês, que está tentando controlar a Internet... Isso é um prêmio para as ideias delirantes! É um bônus para o Pentecostalismo, um bônus à conspiração, um bônus à estupidez, para ficar só nisso. Os Estados não podem, a não ser que se tornem Estados totalitários, obviamente, impedir essa expressão.

Creio que o papel dos Estados é reconstruir procedimentos democráticos, refabricar partidos, refabricar procedimentos democráticos locais, garantir que os cidadãos estejam em condições de cuidar dos próprios assuntos. Mas isso, hoje, é extremamente difícil, porque - como você mesmo pode ver ao seu redor, inclusive em sua universidade - nós observamos certos indivíduos que têm opiniões e indignações extremamente fortes, mas que, em outras ocasiões, fazem praticamente o oposto daquilo que pregam. A crise da democracia consiste em que minhas ideias e minhas práticas podem não ter nenhum vínculo. Ao passo que, dentro de uma democracia, os mecanismos exigem certa coerência. Por exemplo, em nosso campo, que é o campo da educação, você sabe tão bem quanto eu que nós denunciamos maciçamente as desigualdades sociais, porém nós as aumentamos enormemente quando o assunto nos toca diretamente, quando se trata de colocar os nossos filhos nas melhores escolas. Ao mesmo tempo que denunciamos as desigualdades educacionais, nós mesmos as produzimos. Nós denunciamos a falta de miscigenação social, porém optamos por viver em bairros fechados. É isto, portanto, a crise da democracia: é quando a opinião e as práticas deixam de ser coerentes.

D\&D: Uma escola justa, como você propõe, deve levar em conta as desigualdades e exercer alguma discriminação positiva. No contexto da pandemia e do aprofundamento das desigualdades no país, como essa ideia pode nos ajudar a refletir sobre os desafios da retomada da educação?

FD: Não tenho muito a dizer sobre isso, mas acho que a pandemia vai mudar as condições de ensino. Haverá cada vez mais ensino a distância, computadores, coisas assim, e para os governos vai ser um desafio equipar escolas, treinar professores, evitar que uma parte da sociedade utilize a plataforma Zoom e a outra parte nem saiba que isso existe. Creio que, hoje, a coisa é muito simples: temos que aceitar o princípio da igualdade de oportunidade meritocrática e, portanto, temos que aceitar a competição escolar porque as pessoas fazem questão disso, porque ela é justa, apesar de tudo. Mas o que é fundamental mesmo é dar a todos os alunos a mesma formação inicial. É preciso ter o raciocínio de John Rawls, que considera que as desigualdades são aceitáveis desde que os mais fracos tenham o melhor nível possível. Assim, acho que a prioridade não é desenvolver as grandes écoles, os institutos, a prioridade é garantir que aos 16 anos de idade todas as crianças saibam aquilo que têm o direito de saber. Esta é a prioridade: garantir que desde o princípio haja uma igualdade muito forte. Depois disso, certamente haverá desigualdades. Mas, pelo menos, é preciso fazer com que essa igualdade inicial esteja garantida. No entanto, isso ainda está muito, muito longe da mente dos governos atuais que, em primeiro lugar, pensam em universidades, grandes écoles, competição internacional, e deixam milhões de pessoas no vazio. Essa é, para mim, a questão fundamental. 
A segunda coisa que precisamos combater é, sem dúvida, a influência excessiva dos diplomas. É claro que os diplomas têm seu papel, mas eles não deveriam determinar o destino dos indivíduos; a vida não deveria parar quando você deixa a escola. Mas é muito difícil fazer as pessoas entenderem isso, porque o mundo do ensino é o mundo que, por definição, adere à ideologia escolar. Por isso, é tão difícil conseguir que se distanciem das crenças que a escola mantém sobre si mesma.

D\&D: Você acha que, com base na sociologia da experiência, é possível entender quais são os vetores que levam os indivíduos vítimas de discriminação a se unirem coletivamente para reivindicar justiça social e igualdade?

FD: Não tenho muita certeza. O que me parece realmente muito importante, hoje, para as ciências sociais, é relacionar as experiências da vida social com as questões coletivas. O grande perigo, o perigo intelectual, seria existir, de um lado, sociólogos descrevendo experiências individuais: "as pessoas estão infelizes nas favelas", "as minorias estão infelizes"; e, do outro lado, os economistas descrevendo o funcionamento do mundo. Ora, a utilidade da sociologia é manter a conexão entre as experiências pessoais e o funcionamento do mundo. É ser uma sociologia holística, que se interessa pelas estruturas, pelo funcionamento e pelos mecanismos do mundo, e, ao mesmo tempo, uma sociologia muito centrada na experiência dos indivíduos, porque o que nos ameaça atualmente é a dissociação entre as experiências individuais e o funcionamento do mundo. Vou dar um exemplo muito simples: todos nós sabemos, no tocante a como funciona o mundo, que há consideráveis questões ecológicas em jogo e, em termos individuais, queremos manter nosso carro. Pois bem, temos que nos obrigar a articular essas duas dimensões. A sociologia foi interessante enquanto ela fez isso. Ainda estou muito ligado à sociologia clássica, aquela que explicava tanto a subjetividade dos indivíduos quanto o funcionamento do mundo. O perigo, hoje, é que essas duas coisas se separem.

D\&D: Você acha que a teoria social poderia nos mostrar os meios para sair do tempo das paixões tristes, tendo em vista outros momentos de crise democrática vivenciados no passado?

FD: Não creio que os sociólogos tenham qualquer privilégio. Sociólogos devem fazer seu trabalho como sociólogos, e não serem profetas. Mas creio que os sociólogos devem ter em mente - e esta é, para mim, a vocação da sociologia - que é preciso explicar as experiências dos indivíduos por meio dos mecanismos sociais, e os mecanismos sociais por meio das experiências dos indivíduos. Quando os sociólogos fazem isso, eles explicam como as experiências são individualizadas, como isso provoca crises democráticas, como as crises democráticas geram raiva e ressentimento; assim, eles são úteis, o que já é bastante bom! Mas se os sociólogos apenas denunciam as desigualdades, as injustiças, não é que eles sejam inúteis, mas, no fundo, eles sabem aquilo que todo mundo já sabe, então, não nos ensinam nada. Portanto, penso que os sociólogos têm um trabalho a fazer, que é o de compreender, ao mesmo tempo, tanto os principais mecanismos sociais quanto as experiências individuais. Dito isso, eles não estão sozinhos, os economistas, os historiadores, os filósofos, todos têm um papel a desempenhar. Acho que devemos desempenhar esse papel com coragem, porque se tornou muito difícil ser ouvido, porém, não mais para os sociólogos do que para os outros, neste mundo onde todos têm acesso à comunicação, onde as pessoas podem lhe dizer: "mas você não tem nenhum privilégio de 
conhecimento". Está acontecendo, agora, com os sociólogos, o que já acontece com os médicos, quando as pessoas lhes dizem: "mas o senhor não sabe de nada! Porque eu acredito no Yoga!", o que, digamos, é algo um pouco desagradável. Mas penso que é preciso aguentar firme e que temos um dever de esperança. Deixar-se afundar no pessimismo é uma falha moral. É preciso acreditar que as coisas podem melhorar.

\section{Referências}

DUBET, F. L'expérience sociologique. Paris: La Découverte, 2017.

DUBET, F. Le déclin de l'institution. Paris: Seuil, 2002.

DUBET, F. Le travail des sociétés. Paris: Seuil, 2009.

DUBET, F. O tempo das paixões tristes. São Paulo: Vestígio, 2020.

DUBET, F. Sociologia da experiência. Lisboa: Instituto Piaget, 1994. 